\title{
SITC. N
}

\section{ANALYTICAL INSIGHT INTO TALENT MANAGEMENT IN TOURISM AND HOSPITALITY IN THE SLOVAK BUSINESS ENVIRONMENT}

\author{
Michaela Sirková*, Viktória Ali Taha \\ University of Prešov in Prešov, Faculty of Management, St. 17. novembra 1, Prešov, Slovak Republic
}

\begin{abstract}
:
Tourism is of great importance and is considered one of the fastest growing sectors, which has contributed to the enormous increase of international trade in services. This paper deals with talent management in the specific context of hospitality and tourism sector in Slovak organizations. It also highlights the benefits of talent management implementation in this sector and specifies talent management processes used by tourism organizations. The paper draws attention to primary data survey of 87 respondents who were representatives of organizations working in the tourism sector.
\end{abstract}

\section{Key words}

talent management, human resources,

tourism,

organizations,

practices.

\section{Acknowledgements:}

This study was supported by the research grant VEGA 1/0513/14: Research on the possibility of measuring and evaluating the impact of human resource management practices on organizational performance.

\section{INTRODUCTION}

Tourism has undergone significant changes in recent years (due to "discovery" of new destinations) and has become one of the fastest growing and developing economic sectors worldwide and a key determinant of socio-économic development as evidenced by statistics. According to the UNWTO Tourism Highlights 2015, tourism represents 9\% of GDP (direct, indirect and induced impact), 6\% of the world's exports and it employs $9 \%$ of the workforce (1 in 11 jobs accounted for this sector). International tourism (travel and passenger transport) accounts for 30\% of the world's exports of services and 6\% of the overall exports of goods and services. Moreover, inbound tourism is an important contributor to the economic development of numerous countries by creating employment opportunities and further opportunities for development (UNWTO, 2015).

In the report on the global tourism and hospitality industry, the International Labour Organization - ILO (2001, in Nickson, 2007) provides evidence suggesting that the industry globally is largely reliant on "marginal workers", such as women, young workers, casual employees, students, relatively high number of part-timers and migrant workers. According to the World Travel and Tourism Council (2015), declining youth demographics, baby boom generation retirement, rising female labour market participation, general shift towards more highly skilled (in terms of education) labour supply as older, less skilled workers retire, and the potential for reverse migration back to fast growing emerging economies, are the most important trends that will influence the future talent supply in the tourism sector. "Organizations and managers in the tourism and hospitality industry face real challenges in recruiting, developing and maintaining the committed, competent, well-managed and well-motivated workforce focused on offering a highquality 'product' to the increasingly demanding and discerning customers" (Nickson, 2007, pp. 2-3). This requires implementation of talent management i.e. the process of identifying, securing, developing, and managing relevant talent, which is important to meet the organization's longterm strategic goals and ensure short-term productivity (Nilsson \& Ellström, 2012). The functionality and vitality of the company's talent management processes determine how well the company can groom its high-potential employees to fill strategic management roles (Ready \& Conger, 2007).

Talent management has developed as a response to many changes in the workplace such as industrial revolution, the rise of labour unions, globalization or outsourcing (Frank \& Taylor, 2004). The given authors predicted in 2004 that "the real battle to attract, develop, motivate, and retain talent is going to heat up considerably" and "demographic time bomb will make talent management the top priority for organizations" (Frank \& Taylor, 2004, p. 33). Nilsson and Ellström (2012, p. 27) point to the „shift from job security and life-long employment to life-long learning, employability, and talent management". 
The Chartered Institute of Personnel and Development (CIPD) defined talent management as the "systematic attraction, identification, development, engagement, retention and deployment of those individuals who are of particular value to an organization, either in the view of their 'high potential' for the future or because they are fulfilling business/operation-critical roles" (CIPD, 2013). This concept could also be defined as "the capability to create and continuously optimize talent resources needed to execute a business strategy. This means attracting and developing them, guiding their performance towards optimal productivity in light of strategic goals and finding new sources of value in their performance through innovation and continuous improvement" (Sonnenberg, 2010, p. 2). According to Iles (2007, in D'Annunzio-Green, 2008), talent management is defined as a holistic approach to human resource planning aimed at strengthening organizational capability and driving business priorities using a range of HR interventions. These include a focus on performance enhancement, career development and succession planning.

Lewis and Heckman (2006) point out that due to the confusion regarding definitions, terms and assumptions; it is difficult to identify the meaning of talent management. The authors attempted to address the question regarding talent management definition and determined three distinct strains of thought regarding talent management: (1) talent management as a collection of typical human resource department practices, functions, activities or areas such as recruiting, selection, development, and career and succession management; (2) talent management focused primarily on the concept of talent pools i.e. talent management as a set of processes designed to ensure an adequate flow of employees into jobs throughout the organization; (3) talent management perceived more broadly, without regard for organizational boundaries or specific positions (Lewis \& Heckman, 2006)

Human resources (HR) represent real value for organizations and one of the most important assets, while their role is irreplaceable, especially in the services sector. In this context, Bharwani and Butt (2012) point to the crucial role of employees in hospitality sector (all services sectors) since they become part of the service product and contribute to the image of the organization. That is why hospitality industry is considered the human resource-centered industry.

In tourism, as in other areas/sectors, a paradox can be observed. On one hand, we face a lack of jobs, while on the other hand, there is a talent deficiency causing a problem to fill in vacancies (talent vacancies) by skilled and talented individuals. The World Travel and Tourism Council Final Report (2015) states that the talent market in travel and tourism industry is already challenged with high staff turnover, competition with other industry sectors for the best candidates, and in some cases, adverse supply trends, such as declining demographics. New regulations, new technology, shifts in customer service preferences, changing visitor markets and other industry drivers have the potential to transform the type of skills that employees working in travel and tourism industry will need to possess in future and employers will need to train staff in. A thriving travel and tourism sector will require companies and governments to implement and promote proactive and careful talent supply management policies, as well as regular monitoring and projecting of talent demand, supply and imbalances to pre- dict in advance any looming shortages (World Travel and Tourism Council, 2015).

D'Annunzio-Green (2008) notes that the concept of talent management is now recognized as a much broader concept (than original concept focused mainly on recruitment) aimed at attracting, retaining, developing and transitioning talented employees. When taking a look at the talent management processes, preliminary step in talent management strategy is the definition of the organizational talent - specification, designation of those who are considered to be talents i.e. people with potential and a great value for company/organization. It should be noted that there is considerable inconsistency in defining the "organizational talent", because the definition of "talent" is determined by specific organizational conditions and settings, environment in which the organization operates, as well as by different requirements on employees necessary for performing a particular job. Also, according to Baum (2008, p. 720) "talent, in the context of hospitality and tourism does not necessarily mean the same thing as it might in other sectors of the economy". Generally, talents refer to people with high potential, people with specific skills, competencies, abilities, attributes, experiences and behavior, who are able to achieve excellent results, and thus ensure good overall performance, viability and competitiveness of the organization (Ali Taha et al., 2014).

As regards talent recruitment, the World Travel and Tourism Council (2015) recommends to significantly increase the salaries and attract staff from other sectors while underlining that some employee skills are transferable across travel and tourism sub-sectors or from other sectors in the economy, but some talent requirements are more specific and could be supplied from more narrow and well-defined sources. Moreover, flexible recruitment and retention practices are required in the area of workforce planning.

Generally, the following strategies are very effective in managing talent:

- adapting talent sourcing to recruit more untapped talent pools,

- recruiting candidates outside the local region and country,

- partnership with educational institutions to create curricula aligned to talent needs and considering new locations to operate from where a larger and higher quality pool of talent exists (World Travel \& Tourism Council, 2015, p. 20).

\section{RESULTS AND DISCUSSION}

Our study provides analytical insights into talent management in the Slovak hospitality and tourism sector.

Primary data was collected via questionnaire among managers or representatives of 87 tourism and hospitality organizations in Slovakia. Most of the surveyed organizations (71\%) were medium-sized organizations (up to 100 employees), followed by small organizations (22\%) and large organizations (7\%). This composition corresponds to the structure of the organizations in tourism, with predominance of small and medium-sized organizations. Besides size, another important criterion is equity participation, while a sample involves $29 \%$ organizations with foreign capital/property participation. As regards the age structure, one of the most important demographic characteristics of 
employees working in the surveyed organization, majority of employees in tourism are aged 26 - 35 years (43\%); the second largest age groups of employees in tourism are people aged $36-45$ years (34\%). Other age groups are not significantly represented in the workforce of the surveyed organizations, while employees over 56 years represent only $2 \%$ of the workforce. This fact is not surprising, because tourism industry is very dynamic and companies largely employ young people. Another reason is the high proportion of seasonal work in this sector, which is particularly attractive for young people.

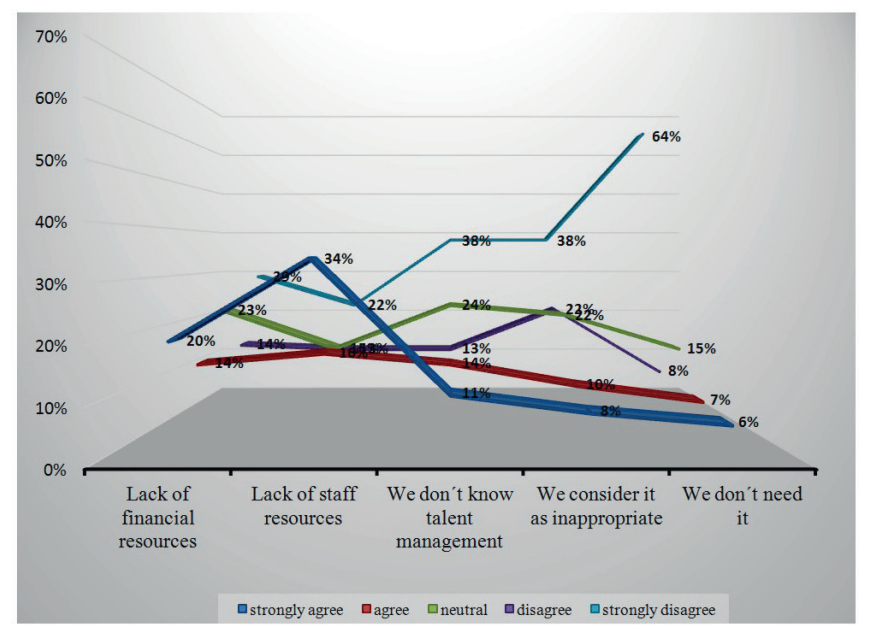

Fig. 1. The reason for non-use of talent management Source: own processing

The survey showed that only $36 \%$ of the surveyed companies implement (to a greater or lesser extent) talent management. Organizations that are not yet implementing this concept were asked about the reasons. The main reason for non-use of talent management is the "lack of human resources" (50\% of organizations chose this option), followed by the lack of financial resources. Figure 1 shows all answers. It should be added that $72 \%$ of these organizations are aware of the need for talent management (disagreed with the statement "We do not need talent management").

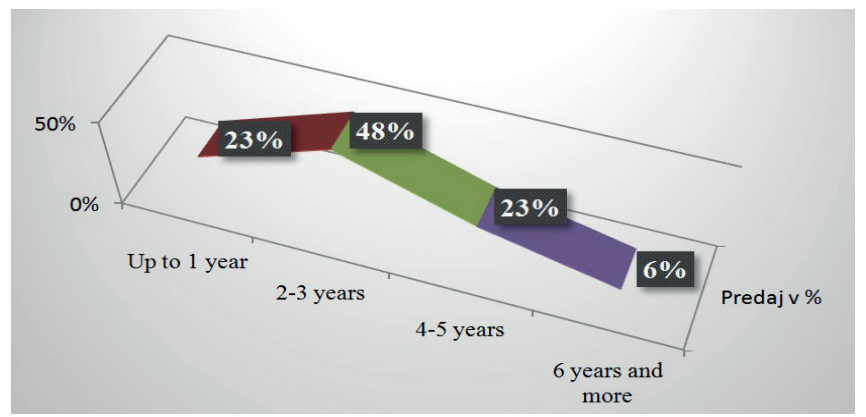

Fig. 2. Length of talent management implementation Source: own processing

In terms of the length of talent management implementation, the majority (48\%) of organizations implementing talent management uses this concept within the range of 2 -3 years. Only $6 \%$ of organizations use talent management for more than six years (Figure 2). Also, this finding is not surprising, as talent management in Slovakia is a relatively "new" concept and has been gaining awareness of the business community only in recent years.

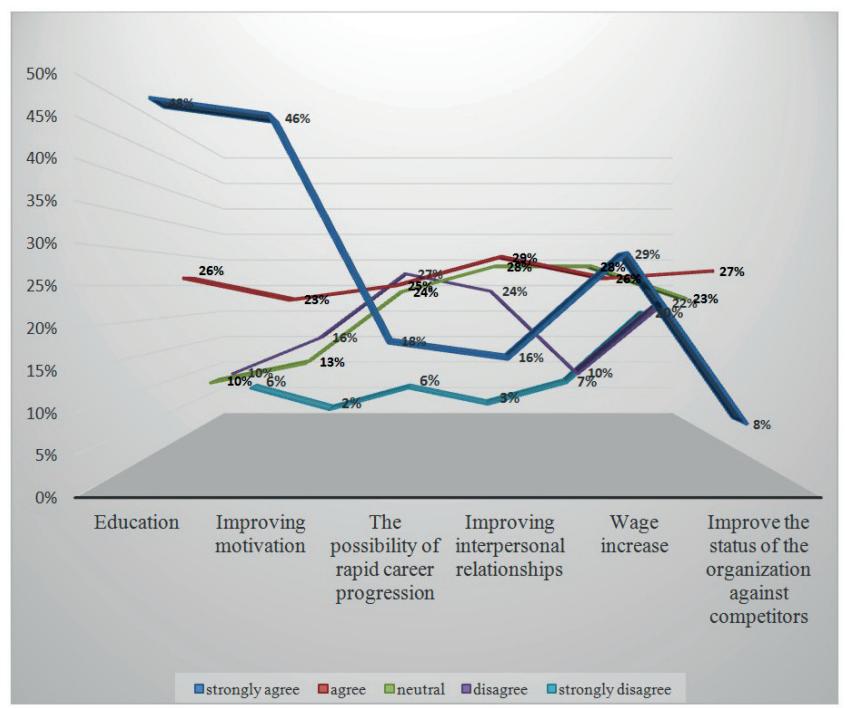

Fig. 3. The benefits of developing talent in organizations

Source: own processing

We have examined the main advantages of talent development. Most organizations indicated that the talent development increased employee willingness to educate and improve their skills and increased employee motivation. Another important "benefit" is the wage increase (55\% of the organizations). Surprisingly, at least organizations indicate "increased competitiveness and better competitive position of the organization" as an advantage of talent development (Figure 3).

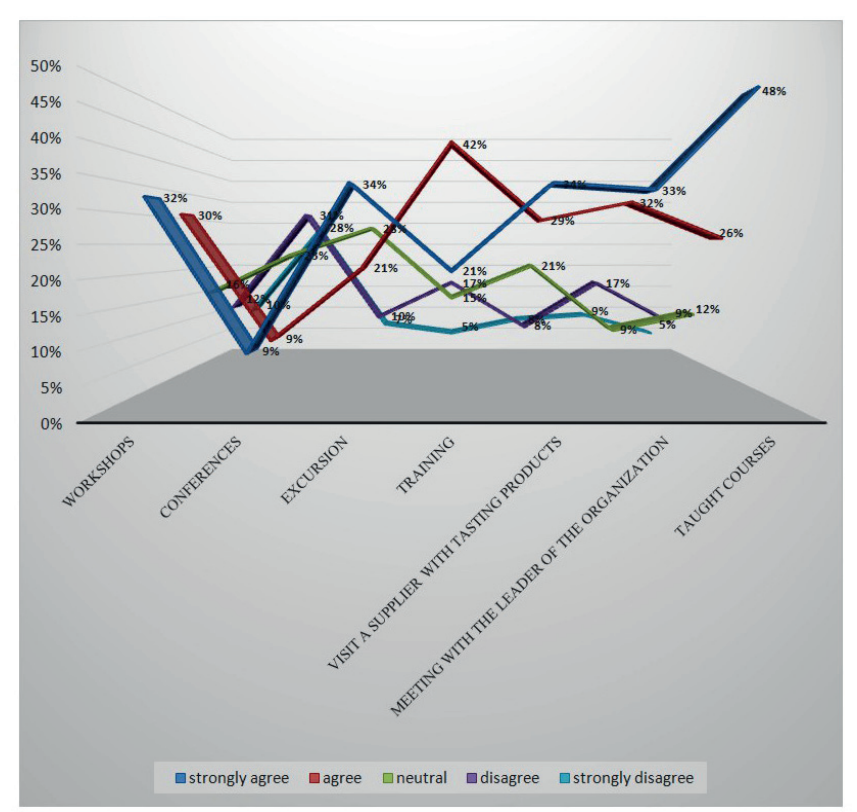

Fig. 4. Methods of talent development

Source: own processing

After that, we investigated the methods of talent development used in the Slovak tourism organizations. According to the results obtained, the most common methods of talent development are "taught courses" and "training". This marked the option agreement and strong agreement of $74 \%$ of organizations.

As can be seen (Figure 4), all organizations have expressed a positive view of the methods of talent development. However, they disagreed or strongly disagreed only 
regarding "conferences", where only $59 \%$ of organizations surveyed this method of development and claimed that is not used or considered it least effective.

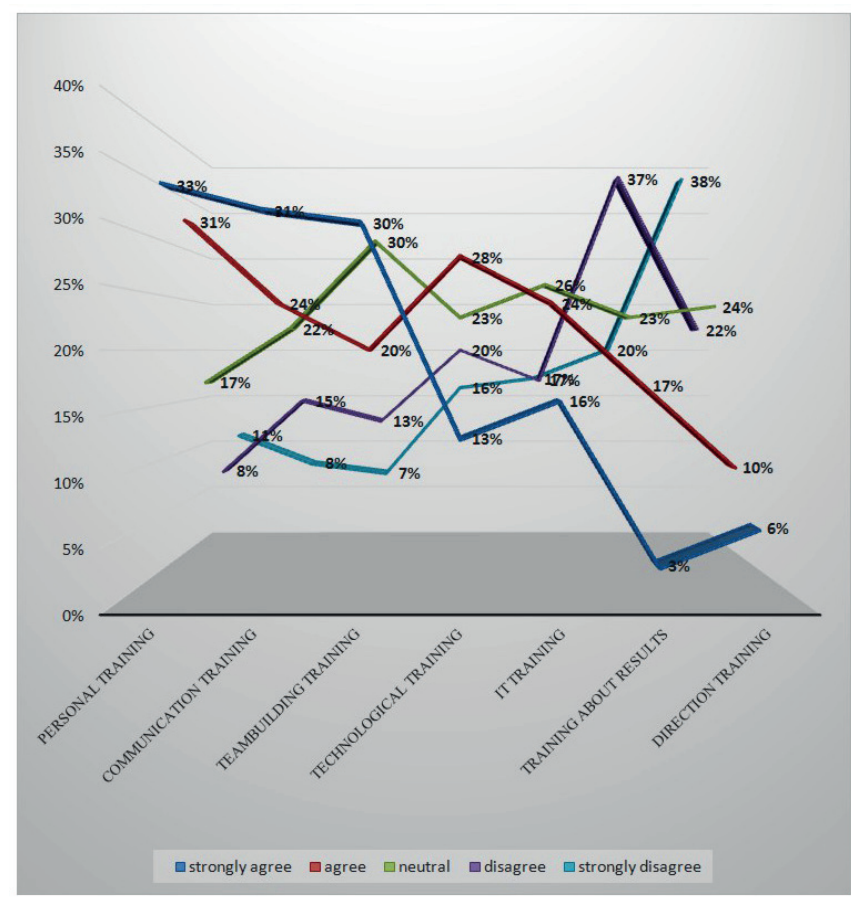

Fig. 5. Type of training

Source: own processing

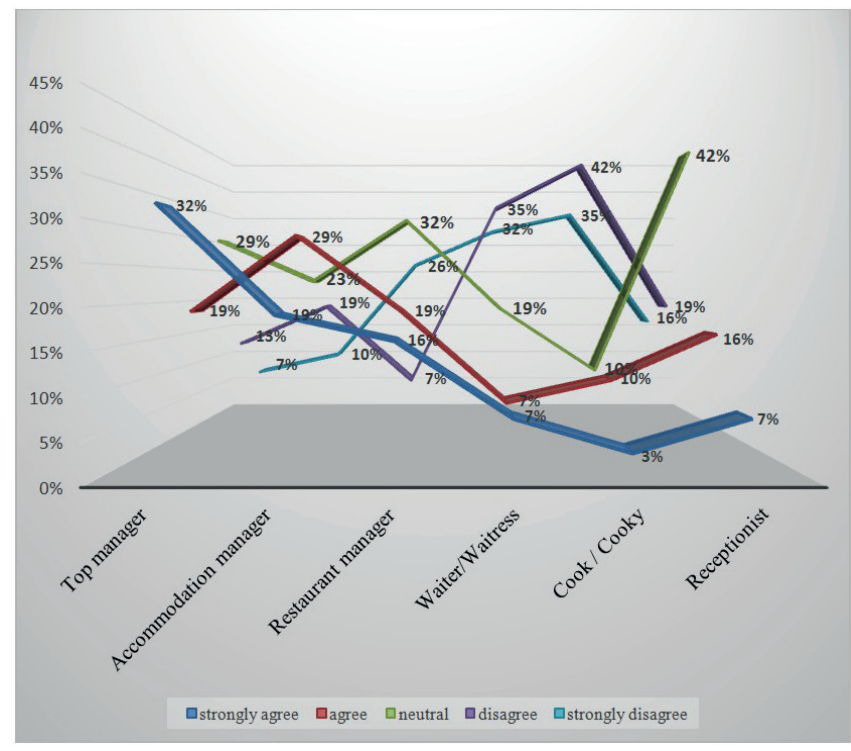

Fig. 6. Positions of hiring and recruiting talents Source: own processing

We then investigated which types of training are most often used. The most common answer was in the affirmative called "personal training". Strong agreement or agreement was provided by $64 \%$ of the organizations, which means that this form of training is most commonly used and mainly focuses on working with people. At the same time and based on the chart, it can be concluded that these organizations also focus on "communication" in the team and "teambuilding". Communication training is used by $55 \%$ of the organizations to avoid undesirable situations not only with customers but also among the staff. As regards "IT and technology training", organizations label these options typically neutral, which means that they consider such types of training not so important for the talent development in the organization.

As can be seen (Figure 5), "direction training" was considered the worst option, as well as "training about the results" and are performed only in some organizations. Namely, $57 \%$ of organizations have expressed negative opinion about this option.

Research results show that organizations most frequently retain and hire talented people for the position of "top/ senior manager" ( $51 \%$ of the surveyed organizations indicate this answer) and "accommodation manager" (48\% of organizations). It can be assumed that both of the abovementioned positions are crucial, and therefore organizations devote considerable attention to filling in these positions and employing talented candidates. On the other hand, the position "restaurant manager" is not likely to be seen as significant because majority of organizations do not need to hire talents for this position (as evidenced by the prevalence of discordant or neutral responses). In hotels or restaurants, the position of "restaurant manager" can be carried out (and often is performed) by the head waiter. This phenomenon is typical for small and medium-sized organizations (which dominated in the survey sample). The least significant positions in terms of talent search and recruitment are "waiter/ waitress" (67\% of organizations), "chef/cook" and the "receptionist". Figure 4 shows the distribution of responses.

\section{SUMMARY}

The tourism business success lies primarily in the quality, accessibility and variety of services provided, as well as on building relationships with customers. This requires skilled, dedicated and committed employees. Employers make every effort to attract, hire and recruit the most appropriate people. Despite the lack of jobs in tourism and masses of the unemployed, talent insufficiency can be observed.

Our analysis leads to some conclusions: (1) over a third of the surveyed organizations use talent management; (2) organizations retain and hire talents mainly for the position of "top/senior manager" and "accommodation manager"; (3) most organizations implement (at least some of processes and tools of) talent management within the range of $2-3$ years; (4) talent development leads to employee willingness to educate and increased motivation. The research findings support the hypotheses that the use of talent management tools and processes are affected by the size of organization, and not by the (foreign) capital/property participation.

\section{REFERENCES}

Ali Taha, V., Sirková, M., \& Bednárová, L. (2014). Talent management in Slovak organizations: insight into selected practices and processes. In: Intercathedra. No 30/2. Poznań (Poland): University of Life Sciences, Department of Economics and Wood Industry Management.

Baum, T. (2008). Implications of hospitality and tourism labour markets for talent management strategies. International Journal of Contemporary Hospitality Management, 20(7), 720-729. 
Bharwani, S., \& Butt. N. (2012). Challenges for the global hospitality industry: An HR perspective. Worldwide Hospitality and Tourism Themes, 4(2), 150-162.

Biswas, M., \& Suar, D. (2013). Which Employees' Values Matter Most in the Creation of Employer Branding? Journal of Marketing Development and Competitiveness, 7(1), 93-102.

Chartered Institute of Personnel and Development - CIPD. (2013). Talent management: an overview. Retrieved Jun 15, 2015, from http://www.cipd.co.uk/hr-resources/factsheets/talent-management-overview.aspx

D’Annunzio-Green, N. (2008). Managing the talent management pipeline: Towards a greater understanding of senior managers' perspectives in the hospitality and tourism sector. International Journal of Contemporary Hospitality Management, 20(7), 807-819.

Frank, F.D., \& Taylor, C.R. (2004). Talent management: Trends that will shape the future. Human Resource Planning, 27(1), 33-41.

Hsu, Y. (2015). The Review of Human Resource StrategiesApplying in Hospitality Industry in South California. International Business Research, 8(3), 133-140.

Lewis, R.E., \& Heckman, R.J. (2006). Talent management: A critical review. Human ResourceManagement Review, 16(2), 139-154. doi:10.1016/j.hrmr.2006.03.001

Moroz, P. (2015). The implementation of talent management in tourism enterprise: Magister thesis. University of Prešov in Prešov. Faculty of Management.

Nickson, D. (2007). Human resource management for the hospitality and tourism industries. Oxford: Butterworth-Heinemann.

Nilsson, S., \& Ellström, P. (2012). Employability and talent management: challenges for HRD practices. European Journal of Training and Development, 36(1), 26-45.
Ready, D. A., \& Conger, J. A. (2007). Make Your Company a Talent Factory. Harvard Business Review. Retrieved Jun 15, 2015, from https://hbr.org/2007/06/make-yourcompany-a-talent-factory

Saar, S.S. (2013). The Challenge of Developing and Retaining Talent. Supply Chain Management Review, 17(2), 8-9.

Serban, A., \& Andanut, M. (2014). Talent Competitiveness and Competitiveness through Talent. Procedia Economics and Finance, 16, 506-511.

Sonnenberg, M. (2010). Talent - Key ingredients. Retrieved Jun 15, 2015, from http://hrpublic.be/images/sites/accenture_talentmngtstudy.pdf

United Nations. (2008). United Nations International Trade Statistics Konwledgebase. Retrieved Jun 15, 2015, from http://unstats.un.org/unsd/tradekb/Knowledgebase/ IRTS-2008

United Nations. (2010). International Recommendations for Tourism Statistics 2008. New York: United Nations Publications.

UNWTO. (2014). Measuring employment in the tourism Industries: Guide with best practices. Madrid: World Tourism Organization.

UNWTO. (2015). UNWTO Tourism Highlights. Madrid: World Tourism Organization.

World Travel and Tourism Council. (2015). Global Talent Trends and Issues for the Travel \& Tourism Sector. Retrieved Jun 15, 2015, from http://www.wttc.org/-/med $\mathrm{ia} / 382 \mathrm{bb} 1 \mathrm{e} 90 \mathrm{c} 374262 \mathrm{bc} 951226 \mathrm{a6618201.ashx}$ 